\title{
Use of ozone therapy in chronic laminitis in a horse.
}

\author{
Clarisse S. Coelho*1, Wherick Abreu Bernadi1 ${ }^{*}$ Antonio M. Ginelli2, Thassio \\ Spagnol ${ }^{3}$, Leandro S. Gardel' ${ }^{4}$, Vinicius R.C. Souza 5 ,
}

${ }^{1}$ Animal Science Master Program, Universidade Vila Velha (UVV), Brazil. ${ }^{2 H o s p i t a l ~ V e t e r i n a ́ r i o ~ R a n c h o ~ B e l a ~}$

Vista, Serra, Espirito Santo, Brazil. ${ }^{3}$ School of Veterinary Medicine, UVV-ES. ${ }^{4}$ Department of Veterinary

Clinics, ICBAS-University of Porto, Porto, Portugal. ${ }^{5}$ Quality Especialidades Veterinárias. Vitória, Espírito

Santo, Brazil.

doi: $10.7203 /$ jo3t.1.1.2015.12164

Received: October, 2015

Published: December 2015

\section{ABSTRACT}

A ten year-old mare, $320 \mathrm{~kg}$, was referred with signs of lameness and reluctance to ambulate. On clinical examination, animal showed signs of shifting weight lameness on the forelimbs, presence of palpable supracoronary depressions and severe signs of pain with hoof test pressure over the sole on right forelimb. Digital pulses and temperature of the hoof were thought to be within normal limits. On inspection it was possible to observe a short extension of the toe and solar prolapse with hoof capsule distortion. Radiologic measurements showed displacement of the distal phalanx $\left(30^{\circ}\right)$. The animal was diagnosed with Obel grade IV chronic laminitis on the right foot. Therapeutic protocol established included exclusively corrective trimming and intramuscular, peritendinous and intrarectal administration of oxygen/ozone therapy as anti-inflammatory therapy. Oxygen/ozone therapy sessions were performed twice a week, for a total of 20 sessions. Six months after original presentation, the mare demonstrated clinical improvement with an improved body condition and better ambulation. Radiologic evaluation showed a normal relationship between the dorsal hoof wall and the distal phalanx.

Keywords: Lameness, Equine, Ozone

\section{INTRODUCTION}

Laminitis is one of the most important causes of lameness in horses and is defined as an inflammation of the laminae of the foot $[1,2]$. According to Moore et al. [3], the use of term "Acute Laminae Degeneration" would be more appropriate. The laminar degeneration of the dorsal wall of the hoof in conjunction with the pull of the deep digital flexor tendon, the horse's weight and locomotion forces promote a ventral dislocation of the distal phalanx from its normal position in the hoof [4]. This disease represents one of the most common and potentially crippling diseases of the

Authors Information

E-mail address: clarisse.coelho@uvv.br adult horse, often resulting in permanent lameness or euthanasia [5].

The actual cause and pathophysiology of this disease are still unknown. Disease processes known to frequently precede the development of laminitis are: gastro-intestinal disturbances, biomechanical alterations, retained placenta, use of steroid drugs and hypothyroidism [1]. According to Johnson et al. [6], these factors can lead to peripheral hypoperfusion, endotoxemia and a local systemic release of cytokines, which can increase metalloproteinase activity. The metalloproteinases promote the enzymatic degradation of the basal lamina cell layer.

The diagnosis of laminitis is based on clinical signs and radiography [4]. To better evaluate the degree and type of rotation, a radio-opaque object should be attached to the dorsal hoof wall and lateromedial and dorsopalmar views should be taken. 
The treatment for chronic laminitis consists in the pain management and the realignment of the hoof structures using trimming and shoeing on the affected limb. There are several types of drugs, shoes and surgical procedures used for the treatment of laminitis [7].

Among the pain management options, oxygen/ ozone therapy has shown positive results. Ozone is a gas composed of $95 \%$ oxygen and $5 \%$ ozone [8], bound to water, oil or used alone. Some researchers have demonstrated the efficiency of oxygen/ozone therapy on lumbar pain treatment [9]. Other studies have shown positive outcomes in pain management for long and short periods of time [10].

Due to lack of previous studies of the use of this therapy in equids, the objective of this article was to report a case of chronic laminitis in a cart horse in which only corrective trimming and oxygen/ ozone therapy were used for treatment.

\section{CASE REPORT}

The study and procedures were reviewed and approved by the Committee of Ethics of the Universidade Vila Velha (UVV), Vila Velha - ES, Brazil (64/2009). A ten-year old mare, $320 \mathrm{~kg}$, was referred to Universidade Vila Velha - Veterinary Medical Teaching Hospital (UVV- ES) "Prof. Ricardo Alexandre Hippler" in Vila Velha - ES, Brazil for signs of lameness and reluctance to ambulate on July 2013. On clinical examination the animal showed signs of shifting weight lameness on the forelimbs, capillary refill time of 3 seconds, reddish mucous membranes, as well as increased heart $(63 \mathrm{bpm})$ and respiratory (40 movements/ minute) rates. Specific evaluation of the right thoracic limb revealed presence of palpable supracoronary depressions and severe signs of pain with hoof test pressure over the sole on the dorsal aspect of the foot. The digital pulses and temperature of the hoof were thought to be within normal limits. On inspection of the sole it was possible to observe a short extension of the toe associated with a solar prolapse with hoof capsule distortion (Figure 1A). Radiologic measurements showed displacement of the distal phalanx $\left(30^{\circ}\right.$ on the right forelimb - Figure 1B). The animal was diagnosed with Obel grade IV chronic laminitis [11].

Therapeutic protocol established included exclusively corrective trimming and oxygen/ozone therapy through intramuscular, peritendinous and intrarectal administrations.

Intramuscular and peritendineous administrations of oxygen/ozone therapy were applied using a calculated dosage of $19 \mathrm{mg} / \mathrm{L}$ in $10 \mathrm{~mL}$ (oxygen valve on $3 / 4$ and doser on 6 ). Then, injections of 10 $\mathrm{mL}$ of the oxygen-ozone mixture were applied in previously clipped and aseptically prepared

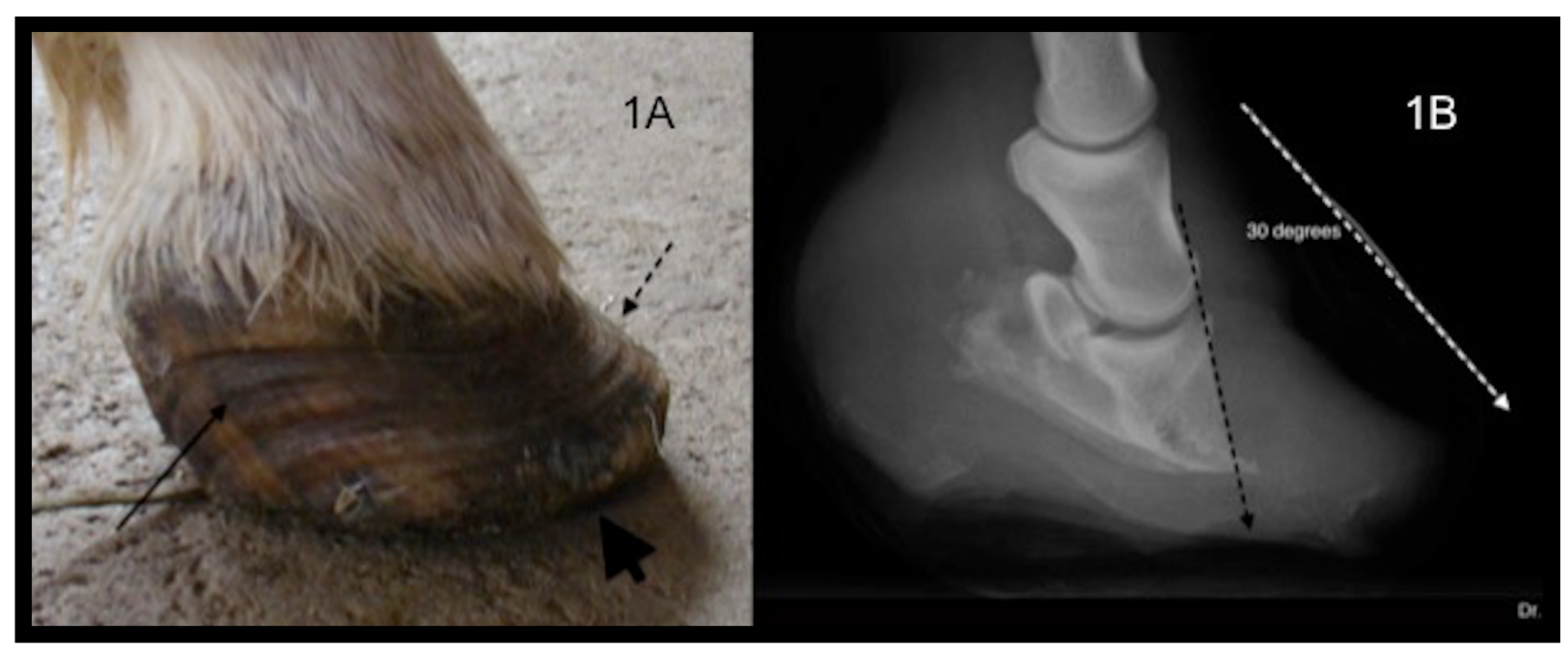

Figure 1. (A) Image of the lateral aspect of the right front foot where it is possible to observe a short extension of the toe (dashed arrow) and solar prolapse (thick arrow) with a hoof capsule distortion (thin arrow). (B) Radiographic examination of the right front foot where it is possible to observe 30 degrees of rotation. 
regions: two suprascapular points, one cranial and one caudal to the scapula on both right and left sides; two points in the scapular region; and one point in the middle of the radius and another near the deep digital flexor tendon.

The ozone protocol was adapted from Bocci [8]. For intrarectal administration, removal of feces and cleaning of the perineal region were carried out before rectal insufflations. The gas mixture was applied over a 5 minutes period and, then the catheter was left in place for 5 more minutes for the gas absorption. This administration was performed using a dosage of $19 \mathrm{mg} / \mathrm{L}$ of ozone in the first two weeks of treatment. After which the concentration was increased in $5 \mathrm{mg} / \mathrm{L}$ per 2 weeks $\left(3^{\text {rd }}\right.$ and $4^{\text {th }}$ weeks $-24 \mathrm{mg} / \mathrm{L}$ of ozone; $5^{\text {th }}$ and $6^{\text {th }}$ weeks -29 $\mathrm{mg} / \mathrm{L}$ of ozone; $7^{\text {th }}$ and $8^{\text {th }}$ weeks $-34 \mathrm{mg} / \mathrm{L}$ of ozone) until the dosage reached $39 \mathrm{mg} / \mathrm{L}$ on the $9^{\text {th }}$ and $10^{\text {th }}$ weeks.

Oxygen/ozone therapy sessions were performed twice a week, on Tuesdays and Thursdays, for a total of 20 sessions, beginning on July 2 nd and finishing on September 5th (total of 66 days of treatment).

Realignment of distal phalanx was achieved through corrective trimming. On July 4th an acrylic resin was fixed to the right thoracic limb toe promoting its extension and moving the weight bearing from the prolapsed sole to the toe (Figure 2). The sole was cleaned daily and the resin was changed every 30 days. When the resin was changed, the hoof wall and sole were trimmed to slowly realign the hoof wall with the distal phalanx, always using radiographic examinations.
On July 30th, an abscess was detected on the sole region of the right foot and it was treated with

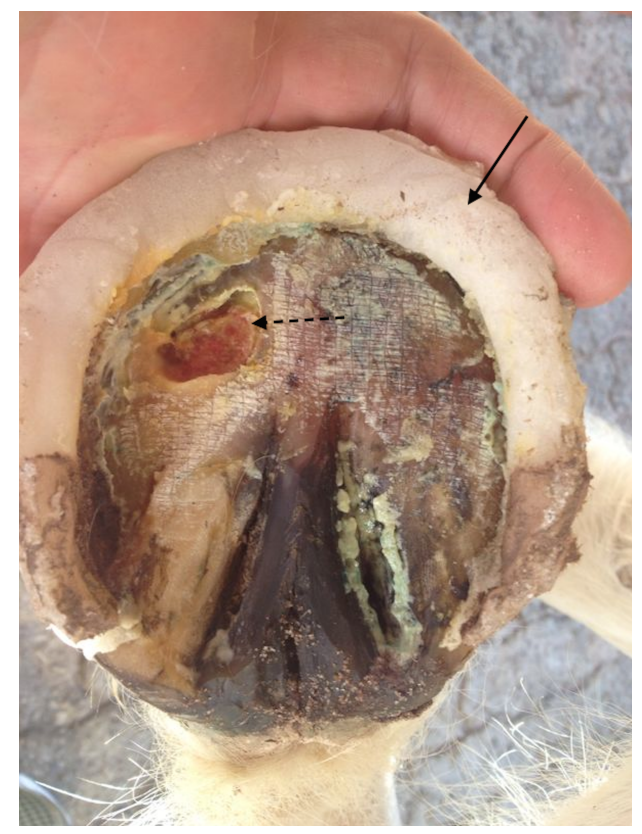

Figure 2. Image of the sole of the right front foot where it is possible to observe the resin attached to the toe, as an extension (thin arrow) and the abscess point (dashed arrow).

success in one month with the use of an osmotic (salt and warm water) footbath and drainage (Figure 2).

On September (2 months after the beginning of the treatment) the resin was removed. Growth of the hoof wall was sufficient for weight bearing (Figure $3 \mathrm{~A})$. On clinical evaluation, heart rate was $36 \mathrm{bpm}$ and the sole had a concave appearance and the pain

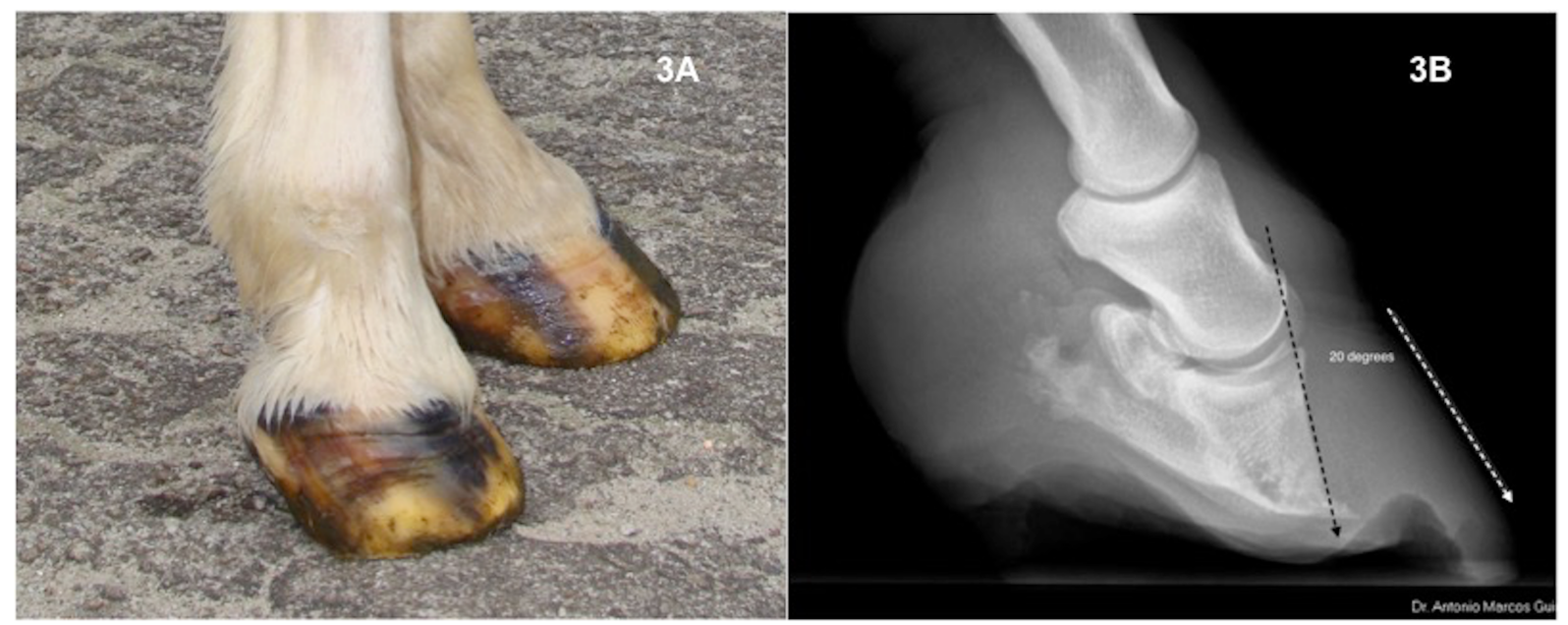

Figure 3. (A) The same hoof after 2 months of treatment with trimming and oxygen / ozone therapy. (B) On the radiographic examination it's possible to observe a reduction of the lesion to 20 degrees. 
was reduced from the time of first presentation (Obel grade II lameness). Radiographic examination revealed a reduction of the distal phalanx displacement to $20^{\circ}$ (Figure 3B). The animal was placed on an oral supplement with biotin (Bio Hoof ${ }^{\circledR}$ 10g/day, Vetnil, Brazil).

Six months after the end of ozone therapy, the mare demonstrated clinical improvement with an improved body condition, better ambulation (still an Obel grade II lameness) and a hoof wall with a better confirmation, solar concavity and no infection. Radiologic evaluation showed a normal relationship between the dorsal hoof wall and the distal phalanx. The mare is currently part of a herd of animals used for the training/learning of students of veterinary medicine at the Vila Velha University (UVV-ES), Brazil.

\section{DISCUSSION}

The oxygen/ozone therapy was the only antiinflammatory therapy used in this case and is presented as an effective therapy associated with corrective trimming for pain control. This therapy has been associated with few adverse effects and can be used in place of nonsteroidal antiinflammatory drugs (NSAIDs) and their associated adverse effects when given for prolonged periods of time. Oliveira Junior and Lages [12] claim that the NSAIDs are indicated mainly in inflammatory conditions; however, their use should be discouraged for a long period of time. NSAIDs are used in horses to treat a myriad of diseases, including colic, respiratory disease, and lameness. Their positive effects include pain relief (analgesia) and the reduction of inflammation and fever, but no NSAID is free of risk even at recommended doses [12]. The main side effects seen in horses occur in the gastrointestinal tract and kidneys. Prolonged high doses of NSAIDs can decrease beneficial prostaglandins and make the horse susceptible to ulceration [13].

According to Iliakis et al. [14], ozone has an effect on the inflammatory cascade by altering the breakdown of arachidonic acid to inflammatory prostaglandins. As a result, by reducing the proinflammatory prostaglandins and the release of bradykinins and alogenic compounds, there is a subsequent decrease in pain [15]. Steppan et al. [16] described that the reduced pain can also be related to the membrane-stabilizing effect of ozone on the pain receptor cells. Ozone has the potential to increase the excitability threshold of the pain receptor cell membranes.
Local regions were used for intramuscular and peritendinous application in the right thoracic limb that had severe phalangeal rotation along with fewer regions of application in the contralateral limb. The contralateral limb was primarily treated to reduce the concerns of overloading from the right front leg. Both local and systemic ozone therapies are recommended by Bocci [8]. Friedman et al. [17] related that the local application of ozonides, unstable, reactive polyatomic anion O3-, might promote the removal of inflammatory phenomena.

The oxygen/ozone therapy in horses is very new and needs further future research. However, there are studies demonstrating the use in human medicine. According to Buliés [18] and Buliés et al. [19], ozone has anti-inflammatory and analgesic actions leading to a prolonged pain relief. The therapy regulates cellular metabolism, provides better tissue oxygenation and has immunomodulation activity. Bonetti et al. [20] conducted a comparative study between the use of corticosteroids and oxygen/ozone therapy in the treatment of 306 patients with low back pain. The technique was highly effective in treating acute and chronic pain and was significantly superior to corticosteroids especially in the long-term pain relief. This was explained by the action of ozone on prostaglandins in patients with low back pain [20].

Oliveira Junior and Lages [12] reported that the oxygen/ozone therapy was effective and had few side effects in treating muscle pain of various etiologies, in particular those related to the accumulation of lactic acid and subsequent reduction in local $\mathrm{pH}$.

Another advantage of oxygen/ozone therapy is that it is economical (20\% of conventional therapy costs with NSAID), which is valuable for the treatment of animals of low commercial value or in situations where the owner may have difficulty paying for expensive therapy.

Based upon the concept established by O'Grady [21], this horse was in the stage of chronic laminitis (Figure 1A). According to White [22], the pain and the degree of rotation of the distal phalanx of the hoof have been associated with prognosis of the disease. If the pain is severe and is not easily controlled by analgesics or support of the hooves (trimming, shoeing, or other support systems), the prognosis is poor. Horses with a rapid response to treatment have a better prognosis than horses with intractable disease. Horses with five or fewer degrees of rotation of the distal phalanx generally have a good prognosis with appropriate treatment. 
Similarly, a rotation of 15 degrees or more is associated with a poor prognosis. Even with severe rotation there have been some horses where realignment of the dorsal hoof wall and the third phalange has been possible, although it can take months of appropriate trimming [22]. In this case report, a mare with a rotation greater than 15 degrees responded very well to corrective trimming and shoeing associated with ozone therapy, gradually reducing the degree of rotation of the third phalanx and decreasing the severity of lameness, and thus providing a good quality of life.

According to Redden [23], the goal of treatment is to restore the biomechanical positioning of the distal phalanx in relation to its correct orientation to the ground and hoof wall. In many cases, the effectiveness of corrective trimming is limited by inadequate depth of the sole and ultimate sole prolapse with significant rotation of the distal phalanx [23]. The horse in this report had shortening of the toe and supported the full weight on the sole, which caused severe pain. For biomechanical treatment of the mare, a lip of acrylic resin was used to extend the hoof wall until the hoof wall could grow long enough to reestablish the concavity of the sole. At the same time the dorsal wall was trimmed in order to realign the third phalanx with the hoof.

The extended length of the hoof wall with the resin that was used in this case report is presented as an advantage over conventional methods using horseshoes and nails. The acrylic application was atraumatic and allowed the precise adjustment by the veterinarian. It can be easily adapted to the conformation and specific requirements of a particular hoof [21]. Other options to redistribute weight exerted on the hoof wall include, atraumatic horseshoes with an oval shaped bar that act as an extension of the heels or heart-shaped bar that provides frog support [24]. O'Grady [25] describes that the horseshoes can be fixed directly on the hoof with poly methyl methacrylate, making the technique less traumatic. These are more suitable in acute laminitis where there is the need to remove the support from the wall transferring it to heels and frog.

The abscess that developed was clinically treated similarly to that described by Belknap [26] According to this author, many cases of chronic laminitis are accompanied by sub-solar infections. In such cases one should take special care to examine the plantar/palmar aspect of the foot to determine the need for drainage. The removal of the sole at the apex of the frog may limit the success of the treatment by exposing the rotated third phalanx [26]. To avoid exposing the third phalanx, all trimming performed in this case was accompanied by radiographs. Hunt [11] describes the importance of the removal of the necrotic material to permit recovery of healthy hoof, while removing the pressure on the affected tissues. Removal of necrotic tissue was valuable in this case.

According to Shallenberguer [27], intermittent lameness responds well to oxygen/ozone therapy. It required 20-30 sessions every 3 or 4 days to have significant pain relief [26]. This treatment protocol was very similar to the one adopted in this case.

Biotin supplementation was provided with respect to the benefits noted with hoof wall growth, as described by Parks [24]. According to this author, biotin has been shown to increase the strength of the hoof wall, which positively affects the treatment of chronic laminitis.

\section{CONCLUSION}

This case report demonstrates that oxygen/ozone therapy showed satisfactory results in association with correct trimming and should be considered as a new successful adjuvant therapy replacing nonsteroidal anti-inflammatory drugs on the treatment of laminitis in horses.

\section{REFERENCES}

1. Baxter G. M. Acute laminitis. Vet Clin. North Am. Equine Pract. 1994;10(3):627-642.

2. Martins-Filho LP, Fagliari JJ, Moraes JRE, Sampaio RC, Oliveira JA, Lacerda-Neto JC. Estudo clínico e laboratorial da fase prodrômica da laminite equina induzida por sobrecarga de carboidrato. ARS Veterinária. 2007;23(1):32-39.

3. Moore JN, Allen D, Clark S. Pathophysiology of acute laminitis. Vet Clin North Am. Equine Pract. 1989;5(1):67-72. 
4. Stashak T. Claudicação em Equinos segundo Adams. 5 ed. São Paulo: Roca; 2006.

5. Johnson PJ, Messer NT, Slight SH, Wiedmeyer C, Buff P, Ganjam VK. Endocrinopathic Laminitis in the Horse. Clinical Techniques in Equine Practice. 2004;3:45-56.

6. Johnson PJ, Kreeger JM, Keeler M, Granjam VK, Messer NT. Serum markers of lamellar basement membrane degradation and lamellar histopathological changes in horses affected with laminitis. Equine Veterinary Journal. 2000;32(6):462-468.

7. Moyer W, Schumacher J. Chronic Laminitis: Considerations for the Owner and Prevention of Misunderstandings. In: AMERICAN ASSOCIATION OF EQUINE PRACTITIONERS CONFERENCE, 46. 2000. Proceedings of the 2000 AAEP. San Antonio: AAEP; 2000.

8. Bocci V. Ozone: A new medical drug. 2nd ed. Heidelberg: Springer; 2006.

9. Buric J, Molino-Lova R. Ozone chemonucleolysis in non-contained lumbar disc herniations: a pilot study with 12 months follow-up. Acta Neurochir Suppl. 2005;92:93-97.

10. Ying WZ, Jiang CM, Wang ZM. Percutaneous treatment of lumbar disc herniation by oxygenozone injection: A clinical study of 322 case. Rivista Italiana di Ossigeno-Ozonoterapia. 2005;4(1):6-8.

11. Hunt RJ. Laminitis in the geriatric horse. Veterinary Clinics of North America. Equine Practice. 2002;18(3):439-452.

12. Oliveira-Jr J, Lages GV. Ozonioterapia em lombociatalgia. Revista Dor. 2012;13(3): 261-270.

13. Dowling P. Myths and Truths About Controlling Pain and Inflammation in Horses. In: Agriculture and Rural Development [Internet], 2011. Available from: http:// www 1.agric.gov.ab.ca/\$department/ deptdocs.nsf/all/hrs3708

14. Iliakis E, Valadakis V, Vynios DH, Tisiganos CP, Agapitos E. Rationalization of the activity of medical ozone on intervertebral disc: a histological and biochemical study. Rivista di Neuroradiologia. 2001;14:23-30.
15. Bocci V, Luzzi F, Corrasdeschi F, Paulesu L, Di-Stefano A. Studies on the biological effects of ozone. III. An attempt to define conditions for optimal induction of cytokines. Lymphokine Cytokine Res. 1993;12(2): 121-126.

16. Steppan JC, Boxley MK, Muto M, Balagurunathan $\mathrm{K}$, Meaders $\mathrm{T}$. Ozone mechanism of action for relieving pain associated with herniated intervertebral discs. J. Vasc. Interv. Radiol. 2009;20(2):16-17.

17. Friedman M, Madden MC, Samet JM, Koren HS. Effects of ozone exposure on lipid metabolism in human alveolar macrophages. Environ. Health Perspect. 1992;97:95-101.

18. Bulies JCE, Diaz OV, Rauder RS, Valdez YL, Garcia CL. Resultados terapeuticos en osteoartritis de la rodilla con infiltraciones de ozono. Rev. Cubana Invest. Biomed. 1997;16(2):124-132.

19. Bulies JCE. Una solucion para exposiciones oseas postraumáticas: asociacion de injerto de epiplon mayor com ozonoterapia. Rev. Cubana Invest. Biomed. 1996;15(2):1-9.

20. Bonetti M, Fontana A, Cotticelli B, Volta GD, Guindani M, Leonardi M. Intraforaminal O2O3 versus Periradicular Steroidal Infiltrations in Lower Back Pain: Randomized Controlled Study. American Journal of Neuroradiology. 2005;26(5):996-1000.

21. O'Grady SE. Realignment of P3 - the basis for treating chronic laminitis. Equine Veterinary Education. 2006;18(4):214-218.

22. White N. Equine laminitis. In: The Waltham International Nutritional Science Symposium, 2005. Available from: https:// www.vetmed.vt.edu/emc/welcome/bios/white/ equine_laminitis.pdf

23. Redden RF. Shoeing the Laminitic Horse. In: AMERICAN ASSOCIATION OF EQUINE PRACTITIONERS CONFERENCE, 43. 1997. Proceedings of the 1997 AAEP. Phoenix: AAEP; 1997.

24. Parks AH. Chonic laminitis. In: Robinson NE. eds. Current therapy in equine medicine. St. Louis: Saunders; 2003.

25. O'Grady SE. Farriery for Chronic Laminitis. Veterinary Clinics of North America Equine Practice. 2010;26(2):407-423. 
26. Belknap J. Treatment of the Chronic Laminitis Case. In: NORTH AMERICA VETERINARY CONFERENCE, 20. 2006. Proceedings of the 2006 NAVC. Orlando: NAVC; 2006.
27. Shallenberguer F. Principles and applications of Ozone therapy: A practical guideline for physicians. Kentucky: CreateSpace Independent Publishing Platform; 2011. 